\title{
Concentration of Danish research funding on individual researchers and research topics: Patterns and potential drivers
}

\author{
Emil Bargmann Madsen* and Kaare Aagaard ${ }^{+}$
}

\begin{abstract}
The degree of concentration in research funding has long been a principal matter of contention in science policy. Strong concentration has been seen as a tool for optimizing and focusing research investments, but also as a damaging path towards hypercompetition, diminished diversity and conservative topic selection. While several studies have documented funding concentration linked to individual funding organisations, few have looked at funding concentration from a systemic perspective. In this article, we examine nearly 20,000 competitive grants allocated by fifteen major Danish research funders. Our results show a strongly skewed allocation of funding towards a small elite of individual researchers, and toward a select group of research areas and topics. We discuss potential drivers, and highlight that funding concentration likely results from a complex interplay between funders' overlapping priorities, excellence-dominated evaluation criteria, and lack of coordination between both public and private research funding bodies.
\end{abstract}

Keywords: research funding, funding concentration, research priorities, diversity, research policy

\section{Introduction}

Across countries research funding systems have undergone major changes during recent decades. As funding plays an influential role in the governance of contemporary science, changes in allocation mechanisms are assumed to affect the scope, content, direction and impact of public research (Gläser \& Velarde, 2018; Sörlin, 2007). Such changes are in turn also likely to influence the distribution of funding across individuals and topics and hence the overall degree of funding concentration.

Current evidence suggests that funding concentration has in fact increased as a result of these changes and that there may be some advantages but also important downsides linked to high degrees of selectivity in the distribution of funding (Aagaard, Nielsen, \& Kladakis, 2020). However, the exact patterns and the potential drivers at aggregated levels are still underexplored.

\footnotetext{
${ }^{*}$ Danish Centre for Studies in Research and Research Policy, Department of Political Science, Aarhus University, Bartholins allé 7, 8000 Aarhus C. Contact: ebm@ps.au.dk. ORCID: 0000-0003-4394-5373

${ }^{+}$Danish Centre for Studies in Research and Research Policy, Department of Political Science, Aarhus University, Bartholins allé 7, 8000 Aarhus C. Contact: ka@ps.au.dk. ORCID: 0000-0003-2983-073X
} 
On the one hand, more pervasive competition, increased performance orientation, stronger emphasis on excellence, and higher reliance on project funding have, across countries, been seen as essential means to optimize the returns on the public investments in science (Wang, Lee, \& Walsh, 2018). These developments are often highlighted as factors that are likely to increase concentration (Aagaard et al., 2020). On the other hand, funding landscapes have also become more diverse and heterogeneous during this period with research depending on, but also made possible through, many different extramural sources such as public research councils, charities, private foundations, and firms (Whitley, Gläser, \& Laudel, 2018, p. 110). A more diverse set of funders, both public and private, could be expected to ensure a more balanced and diverse distribution of funds, because priorities may differ across funding organizations and funding instruments.

However, how this actually plays out in broader settings, where multiple funders interact, is unclear. Existing studies on concentration have so far largely neglected to assess patterns, drivers and consequences at the systemic level. Instead, most studies focus on the concentration of funding, to both individuals and research areas, by analysing grants from only one funder at a time: e.g. the National Institutes of Health (Best, 2012; Bowen \& Casadevall, 2015; Hegde \& Mowery, 2008; Hegde \& Sampat, 2015; Katz \& Matter, 2019; Li \& Agha, 2015; Manton, Gu, Lowrimore, Ullian, \& Tolley, 2009; Stoeger, Gerlach, Morimoto, \& Nunes Amaral, 2018; Wahls, 2018b), the National Science Foundation (Cole, Cole, \& Simon, 1981), the UK Engineering and Physical Sciences Research (Ma, Mondragón, \& Latora, 2015), the Australian Research Council (Bromham, Dinnage, \& Hua, 2016), or the Veni, Vidi, Vici Programme in the Netherlands (Bol, de Vaan, \& van de Rijt, 2018).

While these, and other studies, provide interesting findings, they are unable to address the combined effects of multiple funders. Hence, although the need for comprehensive knowledge about funding priorities across funders often is stressed, the issue has seldom been examined in depth.

We improve on these studies by analysing a set of almost 20,000 grants awarded by 15 Danish research funders between 2004 and 2016. The data encompass almost all major research funding bodies in Denmark. To our knowledge, our study is the first empirical study of the degree of concentration of research funding both for individual researchers and for fine-grained research topics/disciplines considering the majority of relevant funders within a country. From this outset we ask the following research questions:

What patterns of concentration of research funding can be observed across individuals and topics when the majority of funders within a national system are investigated in concert? 
More specifically, we examine the following questions:

- How concentrated is the research funding distributed among individuals?

- Are funding distributions markedly stratified in terms of gender?

- What do the funding configurations of top funded researchers look like?

- How is the funding of the top 100 most funded researchers distributed among universities?

- How concentrated is the distribution of funding across research topics?

- How is the research funding distributed across disease specific research areas?

- To what extent do the observed patterns match measures of disease burdens (which can be seen as a partial measure of societal demand)?

In addition to providing information on these research questions, the analysis also raises a more tentative discussion of the potential drivers of the observed developments.

The paper proceeds by briefly discussing earlier findings on concentration and diversity in research funding in Section 2. We then outline how we combine detailed information on individual grants and grantees coupled with publication data to answer the questions posed above. In Section 4, we first show the degree of funding concentration in Denmark at the individual level and examine the funding configurations of the top funded researchers. Subsequently we proceed by investigating thematic concentration, first at an aggregated level and secondly more detailed by focusing on disease specific research. Here we match the observed patterns with measures of disease burdens to examine whether concentration are driven by societal demands. Based on the total set of findings we discuss potential drivers of concentration in Section 5. In the final section, we highlight our main findings, discuss pros and cons of concentration and derive a series of implications for funding policy.

\section{Previous studies of concentration in research funding}

Concentration of research funding have become a key part of the science policy debate. This is due to multiple factors such as efficiency concerns, austerity policies and a general trend toward greater reliance on grant funding which together have sparked discussions on how best to support scientific discovery. Nonetheless, the systematic, empirically based literature on trends in concentration of grant funding is still in its infancy (Aagaard et al., 2020).

Although fragmented, the available scholarly literature in general appears to document a high degree of concentration of grant funding at the individual researcher 
or group-level. The majority of these studies rely on grant information from the U.S. National Institutes of Health (NIH), and generally show that around $10 \%$ of grantees receive around $40 \%$ of all allocated funding (Katz \& Matter, 2019; Peifer, 2017; Wahls, 2018a, 2018b). While some concentration of grant money consistently has been a part of the system, Katz and Matter (2019) document that concentration has significantly increased over the past 30 years. In 1985, the top $20 \%$ funded researchers accumulated around two times the amount awarded to the bottom $20 \%$, but by 2010 this had increased to 3.5 times (Katz \& Matter, 2019, pp. 10-11). Similar developments have taken place elsewhere. In the UK's Engineering and Physical Science Research Council (EPSRC), $8 \%$ of researchers receive $50 \%$ of all funding, and also here the level of concentration rose steeply between 1985 and 2013 (Ma et al., 2015). Along the same lines two studies focusing on Quebec show how $20 \%$ of researchers amass $80 \%$ or more of total funding across a broad range of disciplines (Larivière, Macaluso, Archambault, \& Gingras, 2010; Mongeon, Brodeur, Beaudry, \& Lariviere, 2016).

Another common finding is an apparent lack of diversity extending to both the type of researcher and the type of research funded. At the individual level, the high concentration of funding results in a bias towards researchers from prestigious institutions. In the NIH case, more prestigious institutions receive $240 \%$ more funding per grantee compared to less prestigious institutions, have a $65 \%$ higher success rate, and receive $50 \%$ larger award-sizes on average (Wahls, 2018a). The lack of diversity in affiliation is also evident in the EPSRC, where a small group of universities form a 'rich club', which attracts the bulk of funding and act as central brokers in collaborations between different universities (Ma et al., 2015, p. 14763). Similarly, high degrees of concentration also seem to reinforce gender biases in grant competitions. Findings from NIH grant competitions show that women are underrepresented research project grantees, have higher risk of not transitioning to the next level, and often transition much later in their career (Lerchenmueller \& Sorenson, 2018, p. 1011).

A second issue related to funding concentration is the possible impact on topic diversity. Observers have long worried that increasing competition for resources, paired with low success rates, incentivise applicants to be more conservative and mainstream oriented in the type of research they apply for (Alberts, Kirschner, Tilghman, \& Varmus, 2014). On a system-wide level, this may at the same time lead funders to invest in a narrow set of topics where capacity already exists and where the probability of obtaining results is high. Studies of biomedical research funding again seem to confirm this notion. Funding from the NIH tend to flow towards research into a select group of diseases, often matching allocation from previous years ( $\mathrm{Yao}, \mathrm{Li}$, Ghosh, Evans, \& Rzhetsky, 2015). In 1996, $10 \%$ of diseases received $43 \%$ of the 
funding budget, with AIDS and Breast Cancer amassing $36 \%$ in total (Gross, Anderson, \& Powe, 1999, p. 1882). By 2006, 10\% of all disease areas still amassed around $40 \%$, with AIDS and Diabetes still being the top funded (Gillum et al., 2011, p. 2). Certain genes are also more likely to receive attention with up to $75 \%$ of projects funded by the NIH relating to only $5 \%$ of human protein-coding genes. This affects individual incentives for choosing genes to study as the probability of becoming a PI is $10 \%$ for researchers studying the least studied genes compared to $25 \%$ for those who studying the mainstream (Stoeger et al., 2018, p. 8).

Funding also more generally appears to skew towards already well-funded topics. Outside the biomedical field, a recent study of grant funding in the U.S. shows a considerably skewed distribution of funding over topics (Klavans \& Boyack, 2017). This concentration of funding correlate well with the prominence of topics in the scholarly literature, but also with the amount of funding a topic has previously attained. By itself, a topic's scholarly prominence in one time period explains over one third of the funding variation in the subsequent period (Klavans \& Boyack, 2017, pp. 1167-1169).

While topic skew signifies a thematic concentration of funding, studies also show a concentration of approaches in the way in which these topics are studied. This is visible in medical research, where different stages of the research pipeline receive different levels of funding. Funding from Danish research councils has been skewed towards translational research (39\%) and basic science $(21 \%)$, while clinical trials only received around 10 \% of all funding between 2012 and 2016 (Rygård, Kjær, \& Perner, 2018). Similarly, focusing on infectious disease research, Head et al. (2016, p. 185) find that $59.4 \%$ of funding in the UK is awarded to pre-clinical research, while funding for phase I-III trials amount to $5.6 \%$.

Finally, the societal impact of a disease only appears to be moderately related to funding intensity (Gillum et al., 2011; Gross et al., 1999). Recent studies actually find a poor match between estimated health needs and funding distributions (Jones \& Wilsdon, 2018, pp. 19-20; UK Clinical Research Collaboration, 2015, p. 49), and this weak link disappears entirely when funding across longer time periods are taken into consideration (Yao et al., 2015, p. 810).

In sum, a growing literature shows that funding tends to be highly concentrated amongst few researchers, topics, and approaches. However, the available studies are skewed towards a limited number of disciplines and countries and most importantly, there is very limited evidence of such patterns at the systemic level. Furthermore, 
empirically based studies of drivers of concentration are also still lacking. These issues are examined in section 4 and 5 of this article.

\section{Methods and data}

\subsection{Data on competition-based grants}

The present study relies on a database of 19,399 research grants awarded by 15 public and private Danish research funders over a period of 13 years from 2004 to 2016. The group of funders encompass both public research councils, private foundations with corporate interests, and non-profit foundations or societies. In addition, also ERC grants are included as they in a Danish context are perceived as a central part of available funding sources and as some of the most competitive and prestigious grants. The total awarded grants amount to 52.9 billion Danish Kroner (7.08 billion euros or 7.7 billion dollars) distributed to 7,539 grantees. It is, however, important to note that this sample is not a complete picture of all grants awarded by Danish research funders within the period. Many funders award money to projects that are not strictly research-related or aimed at producing a traditional scientific output. For that reason, we have excluded all grants aimed at training or education, as well as grants with a monetary value below 50,000 Danish Kroner (6,700 euro or 7,400 dollars). The bulk of these grants are small travel grants or grants to students ('skolarstipendier').

For all grants, we standardised the grant sums to be in Danish Kroner and current prices. For grants with a running amount paid each year, we summed these to one grant sum centred on the grant year. In addition, it is also important to highlight that grants are linked to the main recipient only (typically the PI). For this and other reasons the database has less comprehensive coverage of strategic and innovationrelated funding, as these types of grants are often awarded to a consortium of firms and research organisations without a single discernible PI. Consequently, some underrepresentation of these sources is likely. Furthermore, the focus on PI's only also means that our analyses cannot account for how the funding is spread across researchers after being awarded to a PI.

After establishing the database, grant recipients were manually disambiguated and linked to grants. For common combinations of names, the grantee was identified through a combination of data on their institutional affiliation and primary research area. If not successfully disambiguated through this, grantees were considered separate individuals even if names matched. Throughout the disambiguation process, we also established the gender of the grantee for $97 \%$ of all individuals. In addition, a number of infrastructure grants and PhD- and Postdoc block grants were awarded to deans or rectors. These grants cannot reasonably be treated as grants to individuals. 
They were instead assigned to an institution and kept out of the individual level analyses.

Despite these limitations, the database covers a large part of all external funding awarded to Danish researchers from 2004 to 2016. Comparing the data from 20122014 to self-reported sums spent by the funders in that period, a coverage of around $2 / 3$ of all grant sums is found (UFM, 2016). These are likely not completely overlapping, but shows that the coverage of central funding organs is consistent across time. Although not all funders had equally accurate data of their grant history, we believe that the overall trends of the aggregated distribution of research funding are quite valid. Hence, while the data may not accurately depict the absolute amount of funding awarded, it provides important insight about the relative distribution of scarce resources in the Danish system. Again, however, there is a caveat linked to the strategic and innovation oriented research funding, where both the absolute and the relative distributions are more uncertain.

\subsection{Connecting grants and outputs}

Few Danish funding organizations have consistent ways of classifying the research topics funded by their grants. Hence, in order to ascertain how funding is distributed across different types of research we rely on journal articles and reviews published by the grantees. To link each grantee to their publications, we use a combination of automated and manual matching, by comparing names, e-mail addresses and institutional affiliations in the CWTS in-house version of the Web of Science (WoS). Using this method, we matched 5,773 grantees, and 14,103 grants, to their publication profiles. Together, these grants account for around $80 \%$ of the combined funding amounts attributed to individual principal investigators. Most of the non-matched grants were awarded to research within the humanities and social sciences, which have less extensive coverage in the WoS (Mongeon \& Paul-Hus, 2016). The full and the WoS-matched sample are predominantly similar in their composition. The WoSmatched sample have $2 \%$ fewer female grantees, the grants tend to be a little larger, and have a higher percentage of research grants (vs. e.g. Postdoc grants). The differences are however negligible. Table A1 and A2 in the appendix provides a more detailed comparison of the two samples.

In the analyses below, we use the publications by each grantee in order to attribute them to a research area or a specific research topic. This entails some methodological choices. We assume that a principal investigator's publications reveal the underlying topic, or mix of topics, of the grant. We also assume that the topic mix have not changed much from grant proposal to publication output. However, using the publication output may also carry the advantage that we are assessing the type of research a grant actually resulted in, instead of just the intended results. Furthermore, 
because publications may span multiple areas and topics, we may better represent cross-disciplinary research grants. A grantee's publication output will not be a perfect representation of the topicality in a grant, but is expected to yield a reasonably accurate estimate of topic spread at the aggregate level. We only consider the publications 0-4 years after a grant was received. This approach leaves us with $63.3 \%$ $(12,269)$ of all the collected grants.

For studying the concentration of funding in different research areas and research topics we rely on two categorization schemes. For categorizing each grant within a research area, we use the WoS OECD Category Scheme of 39 research areas categories. ${ }^{3}$ The categories are based on the 250 journal classifications in the WoS database. For publications in multidisciplinary journals, we investigated the most common category of all references in a paper and assigned it to this.

In the article, we furthermore conduct a small case study of disease-specific research. The Danish system in addition to public funders also comprise private research funding foundations tied to pharmaceutical companies. Disease-related funding then provides the opportunity to compare how priorities of public and private funders overlap. Through publications, we were able to match 4,108 grants, spanning 15 funders, to one or more of the 134 disease areas used by the WHO in assessing global burden of diseases. ${ }^{4}$ The classification of papers into disease areas are based on data from Yegros-Yegros et al. (2019) which translates Medical Subject Headings from the PubMed database into ICD-10 (International Classification of Diseases) categories, and finally into disease areas.

For each grant, we weigh both the grant sum and the grant itself according to the proportion of publications within each research area or disease category. For example, a grant of a 1.000,000 DKK with three publications within chemistry (60\%) and two publications within nanotechnology $(40 \%)$ is divided so 0.6 grants and 600,000 DKK is attributed to chemistry, and 0.4 grants and 400,000 DKK is attributed nanotechnology. Finally, following previous studies we use data on the burden of disease categories to investigate how funding aligns with (imperfect) measures of societal health needs (Cassi, Lahatte, Rafols, Sautier, \& de Turckheim, 2017; Evans, Shim, \& Ioannidis, 2014; Gillum et al., 2011; Gross et al., 1999; Yao et al., 2015; Yegros-Yegros et al., 2019). This is done by comparing research output for a disease to its burden in Disability-adjusted life years (DALYs). DALYs are a common measure of disease burden that estimates the equivalent number of healthy years lost due to disability or early death (Gillum et al., 2011). It sums both the Years of Life Lost (YLL) and Years Lived with Disability (YLD) estimates for each disease. We

\footnotetext{
${ }^{3}$ http://help.prod-incites.com/inCites2Live/filterValuesGroup/researchAreaSchema/oecdCategoryScheme.html

${ }^{4}$ https://www.who.int/gho/mortality burden disease/en/
} 
match DALY estimates from the 2017 Global Burden of Disease Study (GBD 2017 DALYs and HALE Collaborators, 2018) to the 134 disease categories from the WHO, and convert these to relative burdens by summing DALYs from all diseases and calculating the share of total burden attributed to each disease.

In this study, we use DALYs as a rough proxy for the societal relevance or importance of a disease category. However, while widely used, DALYs are also a heavily criticized health metric. Outlining a comprehensive critique of the DALY measure is beyond our scope, but we highlight a few salient issues. From a methodological standpoint, the DALY calculation relies on a set of strong assumptions of which not all necessarily are agreed upon (Anand \& Hanson, 1997; Parks, 2014). The calculations are furthermore characterized by a great deal of uncertainty and can be an inaccurate measure of disability in e.g. high mortality regions, because the underlying data are rough estimates or simply missing (Parks (2014). The DALY also have several shortcomings from a conceptual perspective. Firstly, by pooling YLL and YLD estimates, the DALY indicator conflates death and disability into one scale with premature death as an extreme case of disability. Each single case of a disease is also discounted based on the person's age, and case contributions to the DALY estimate thus varies. In sum, the DALY measure relies heavily on a 'cost effectiveness' rationale in both how it is calculated and what this implies conceptually. Such a rationale can been seen as an inherent political choice, where other rationales, such as 'equity', could be equally or more appropriate. Nevertheless, DALYs can provide a reasonable measure of health burden in Denmark, as we are not comparing health burdens to other contexts, and expect underlying data to be reasonably well-curated. Our aim is not to argue for a distribution of research funding according to DALYs, but rather to contrast the distribution of funding to an indication of societal needs. However, we acknowledge that by comparing burden and funding, there is a risk that we appear to legitimize some of the criticized implications of the DALY.

\section{Analysis: Concentration of Danish research funding \\ 4.1 The Danish system for funding research}

The Danish research funding system is fairly pluralistic and consists of many different funding channels, many individual funding programmes and a variety of specific funding mechanisms. This organization reflects a need to serve different societal purposes, the involvement of a broad array of sectorial interests and an aim to underpin a variety of different outcomes. However, in line with the general international development the Danish system has also become more competitive over time. Most importantly, a development was started in 2006 towards turning the existing 65/35 balance between institutional funding and external funding into an 
approximately equal 50/50 balance (The Danish Government, 2006). Secondly, a substantial part of this increasing share of competitive funding was channelled into several newly established research funding organizations, which were institutionalized alongside the traditional research council system and the Danish National Research Foundation. Recently, these research-funding organizations have been merged into one, namely the Innovation Fund Denmark (established in 2014). Accordingly, Denmark now has a rather sharply divided research funding system with a clear distinction between response mode funders and more mission or innovation oriented funders. In addition, the Danish research system has for many years benefitted from a strong and varied sector of non-profit and private research funding foundations. This has in particular been the case for the biomedical research, but also most other areas have at least to some extent benefitted from these non-public funding organizations. The importance of the private research foundations have in particular surged over the past 10 years. Funding from private foundations now comprise almost $20 \%$ of all research funding financing public research activities, and close to $50 \%$ of all competitive funding (The Danish Council for Research and Innovation Policy, 2020). The most recent part of this development is, however, not captured in the present analysis, which only covers funding information up until 2016.

\subsection{Concentration of funding at the individual level}

In the investigation of the concentration of competitively awarded research funding, we first focus on the number of grants and the amount of funding for each individual grantee in the database. Here we observe a significant skew of resources. Among all 7,539 grant recipients, only 3,000 have been awarded two grants, 1,600 have more than two, and 600 individual researchers won five grants or more during the period. In the absolute top end 140 principal investigators (PI) have amassed more than ten grants, and a small selection of these have close to 30 . In total, $20 \%$ of the grantees were awarded $50 \%$ of all grants.

This level of concentration is even more pronounced when focus is shifted to the total amount of funding for each PI. Figure 1 shows the cumulative share of funding for grant recipients as a Lorenz-curve. A straight line would signify total equality in funding amounts, but the graph instead shows significant stratification among researchers. The blue curve shows the distribution for all 7,539 grantees, where the 20 $\%$ most successful receive around $75 \%$ of all funding, while the remaining $80 \%$ share the remaining $25 \%$. This marked concentration of funding at the individual level does not take into account the number of researchers who have either not applied for or not won external research funding. To estimate the concentration of funding across the entire population of Danish researchers, we therefore identified 21,000 publishing scientists with a Danish affiliation and at least five publications in the 12-year period in the Web of Science. As a back-of-the-envelope calculation, this yields a tail of more 
than 13,000 researchers with no external funding. In figure 1, we have included three more or less conservative estimations of the number of researchers: 15,000, 20,000, and 25,000 . Even when using the most conservative benchmark of 15,000 active researchers over this period, we see very high degree of concentration. The top $10 \%$ attracts around $75 \%$ of all funding, while the top $20 \%$ amass just shy of $90 \%$ of the total amount.

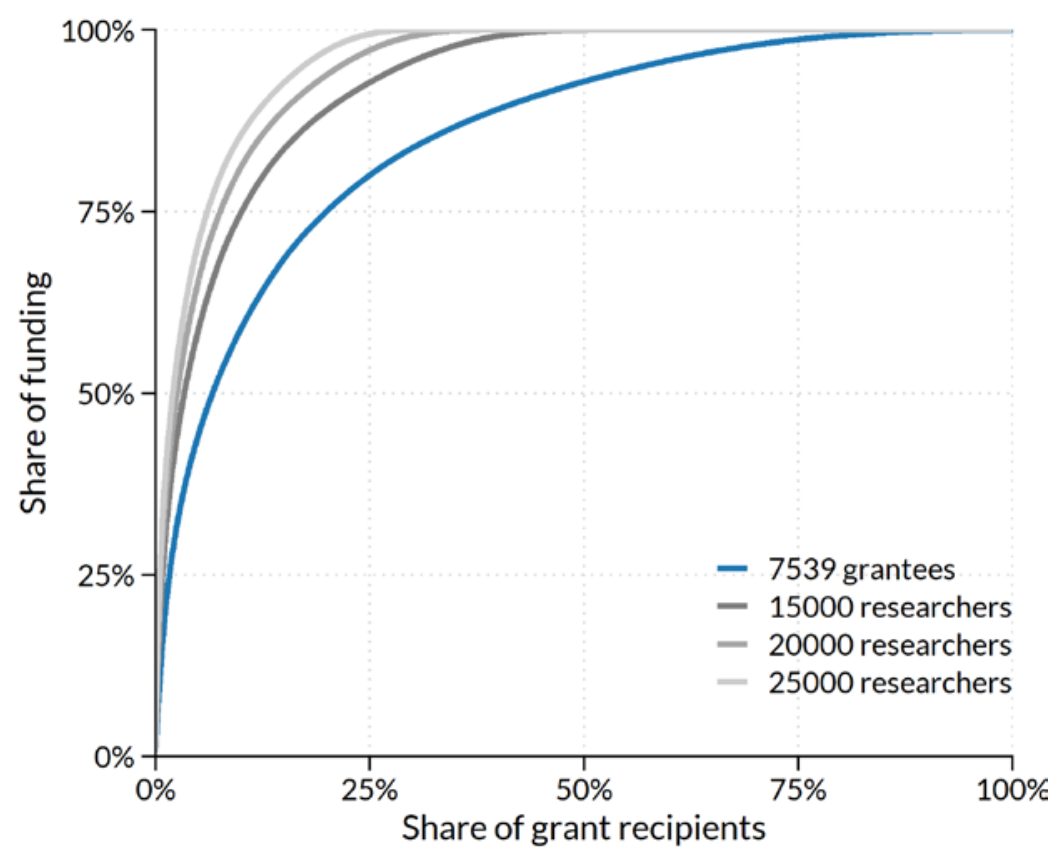

Figure 1. Cumulative share of funding for grantees and estimated population of researchers

The stark degree of concentration can also be shown in terms of the average amount of funding awarded to each grantee. Figure 2 shows the mean funding amount for six ranked groups of researchers. The top 100 researchers each have an average of more than 90 million DDK per person. The group from 101-500 have an average of around 30 million per person, while the 501-2000 group on average have a little less than 10 million to their disposal each. Further down the distribution the average funding amount per person is negliable or non-existent. However, as highligthed in section 3 many of these researchers may indirectly benefit from the grants as team members of succesful PI's.

Besides the average funding amounts, figure 2 also shows a clear gender bias. Only 16 women are among the top 100 principal investigators, and the next group of 400 researchers included only 60 . Hence, as the average amount of funding drops, the proportion of female PIs instead rise. 


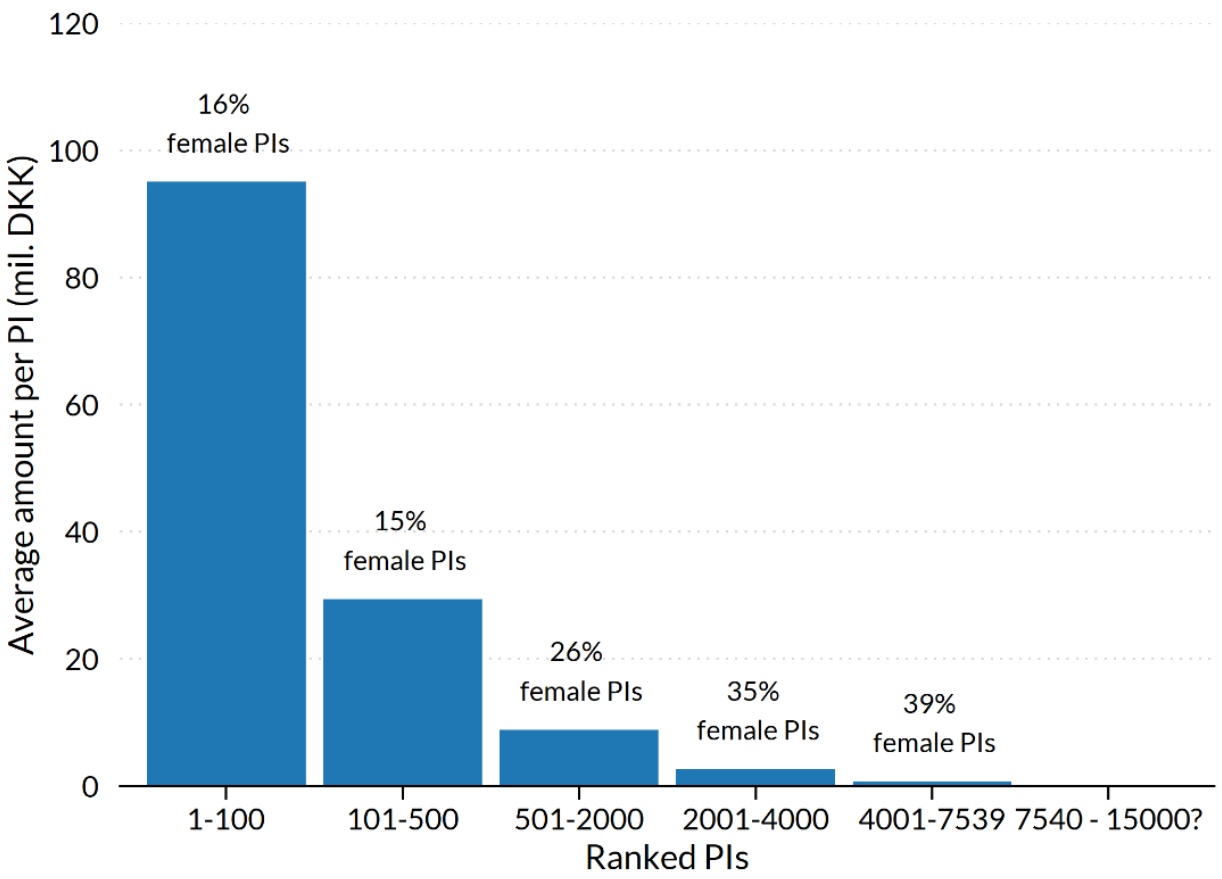

Figure 2. Average amount of funding for grantees and estimated population of researchers

This pronounced lack of gender diversity does not reflect the population of danish researchers. Figure 3 shows the proportion of female and male researchers in population $^{5}$ as full-time equivalents (FTE), and compares these to the proportions of female grantees, the proportion of grants awarded to female grantees, and the proportion of funding amounts awarded to female grantees. Overall, $40 \%$ of Danish researchers are female while this is the case for only $34 \%$ of the grantees. However, when considering the the distribution of grants and funding amounts, only $29 \%$ of all grants have a female PI, and only $22 \%$ of all funding is allocated to a female PI. Dividing these distributions into broad research areas reveals that lack of diversity in the system trails the lack of diversity in the Natural, Technical and Health Sciences. While the proportion of female reseachers are fairly similar in the Humanities and Social Sciences, the increased narrowing from FTE to funding amounts are pronounced in the harder sciences. This also coincideds with distribution of female researchers in different career stages. In the Humanities and Social Sciences, the proportion of female associated professors is twice as large as in the hard sciences, and the same is true for full professors.

\footnotetext{
${ }^{5}$ Average for 2007-2015 based on numbers from Statistics Denmark
} 

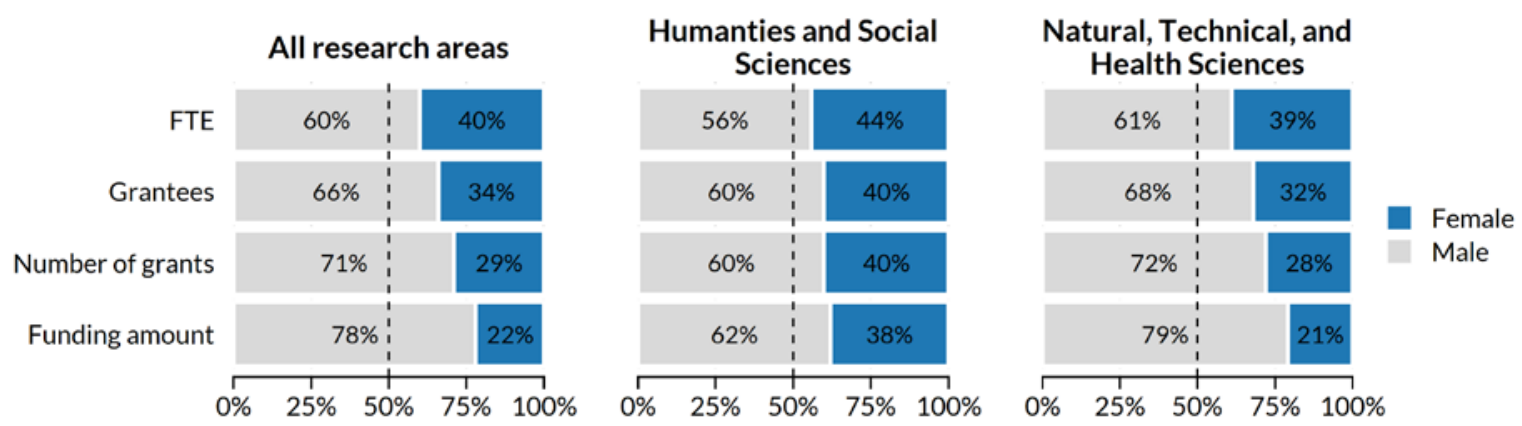

Figure 3. Proportion of female researchers among population (FTE) and grantees, and proportion of grants and funding amounts for female researchers.

It can also be observed that the grantees' career stage seems to be an additional factor leading to stratification. As an imperfect measure of each grantee's 'academic age', we calculated the maximum number of years from their latest grant to their earliest publication for 4,047 researchers with 11,047 grants. A researcher with an academic age of five years have accumulated a median of 1.5 million DKK in grant funding, while a researcher with an academic age of ten years generally accumulates 4.2 million. Moreover, the distribution of funding becomes much wider for higher academic ages. Table A3 and Figure A1 in the appendix show that $50 \%$ of cumulative funding is contained within the interval $[1,995,208-$ $10,331,734]$ for ten years of academic age. For 15 years, the interval is $[3,959,349-20,939,255]$. These numbers should however be interpreted with some caution. A significant number of grantees were not matched to previous publications, and the while these tend to have lower levels of funding, the distribution within this group varies a lot (see Figure A1).

\subsection{Funding configurations of top funded researchers}

Returning to the small group of the top 100 funded researchers, we also note that this group of grantees separate themselves from the rest by the configurations of their funding. First, the top 100 tend to win grants with higher monetary values. Figure 4 shows the distribution of all grants awarded to the top 100 and the remaining group of grantees, with the median funding amount in black. The top 100 funded researchers tend to have a higher median grant amount. Where the remaining grantees tend to win grants of around one million DKK, the central tendency for the top 100 is 2.7 times that. However, the distribution also shows that the top 100 combines both very large grants with numerous smaller ones, as evident from the large overlap between the distributions. On average, the top 100 receives almost seven grants and a median of 5.5 , while the remaining group receive an average of two grants but a median of one. The top funded also attracts funding from more funders with an average of 3.2 compared to 1.3 . 

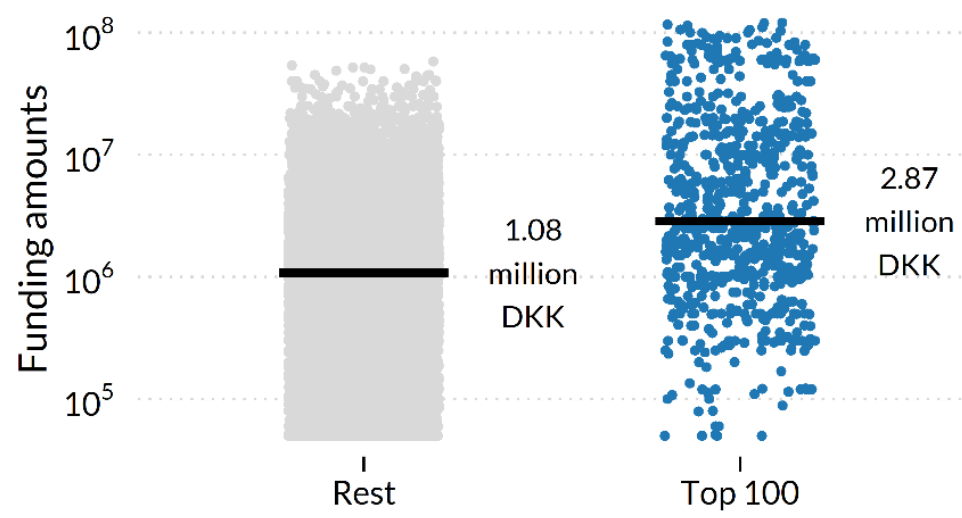

Figure 4. Distribution of funding amounts with median funding amount in black

Second, Figure 5 shows the configuration of unique public and private funding sources among the top 100 funded PIs and the remaining. Within the top 100, the diversity of funding sources are much larger than in the remaining group, with an average of 1.8 private funding sources and 2.2 public, compared to 1.2 and 1.1 among the rest of the grantees. However, the most interesting pattern emerges from the configuration of funding from different sources. Outside of the top 100, $88 \%$ of grantees are funded by no more than one private and one public funder. Actually, 77 $\%$ are only funded by one funder of either domain. In the group of top funded researchers, the configuration distribution is much more spread out. $47 \%$ of these grantees are funded by two or more funders from both domains. In essence, the configuration of funding sources is much more diverse among the well-funded scientists, and much more concentrated outside the top 100 group. The biggest concentration within the top 100 is, however, still centered on one public funder (18 $\%$ of PIs). This reflects a group of grantees whose main source of funding is a large Excellence Centre grant from the Danish National Research Foundation. These grants exceeds 20 million DKK, but are often much larger with a median of 65.75 million DKK.

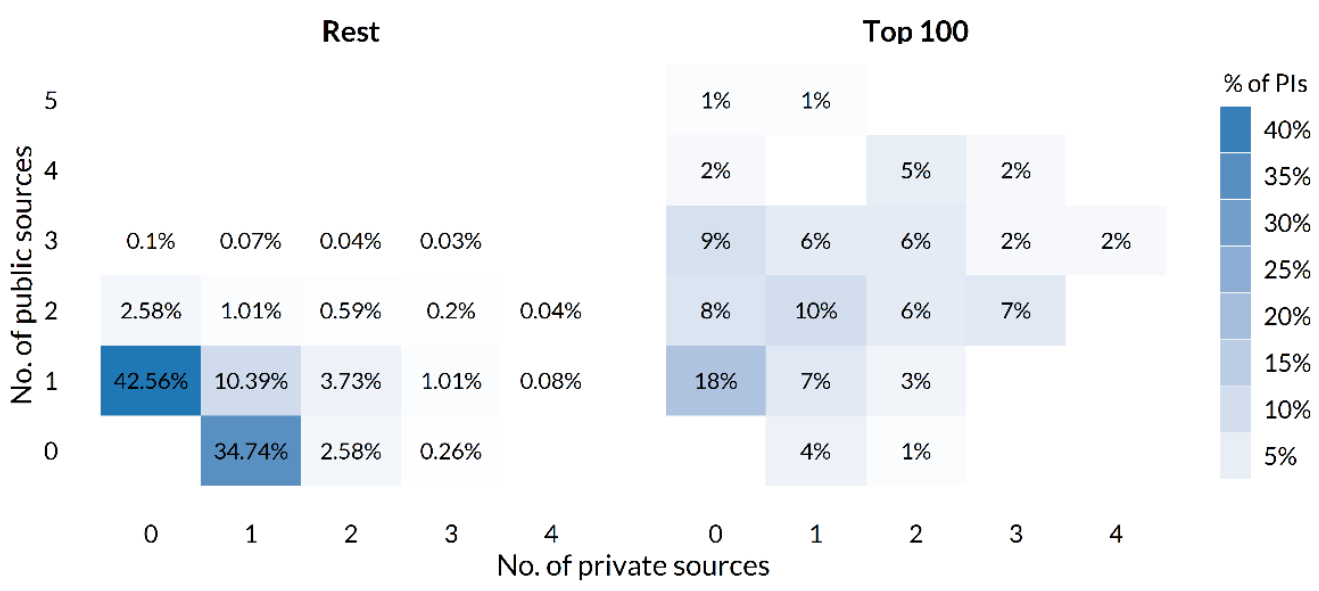

Figure 5. Configuration of distinct funding sources 
Finally, with regard to the top 100 it is also interesting to examine to what extent the grant income of these researchers are concentrated within a few universities. As highlighted in Section 2 studies from the US and UK have found a strong bias towards a small group of elite universities. As can be seen from Figure 6 this is however not the case in Denmark. While the largest and most research-intensive universities obviously account for the biggest share of the total amount of grant income allocated to the top 100, they do not receive a disproportional share. This likely reflects a Danish university system which is much less stratified than Anglo-Saxon systems and the fact that the relatively low number of universities all are research universities.

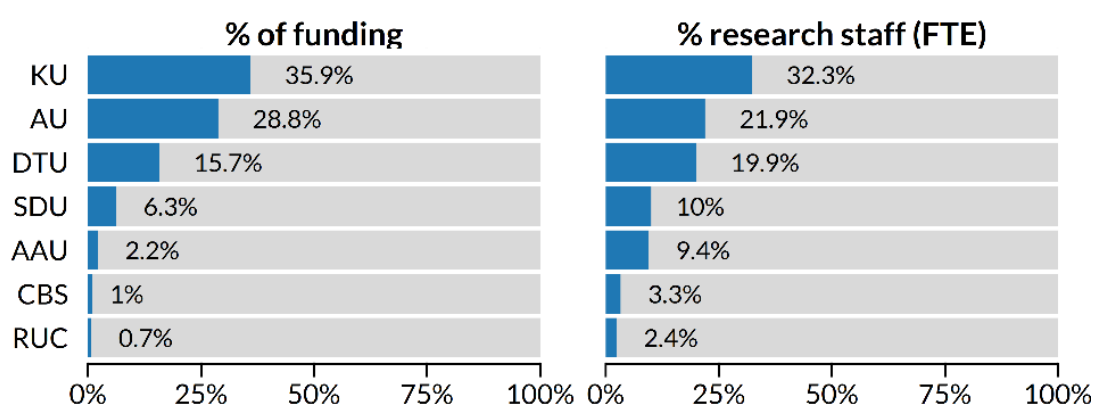

Figure 6. Institutional distribution of funding in top 100 compared to \% of total research staff in university sector.

\subsection{Concentration of funding on research topics}

A following question is how these allocation patterns influence the systemic diversity of research areas and topics. Figure 7 shows a disciplinary map of 12,269 of the grants in our dataset. These are the grants we could link to one or more publication(s) in the four years succeeding a grant. Each bubble or node represents a research area, based on 39 categories from the OECD Frascati manual, and the links between them are the citation traffic between each area. Overall, the figure shows a marked skewness of competitive funding towards the biological and medical sciences. 


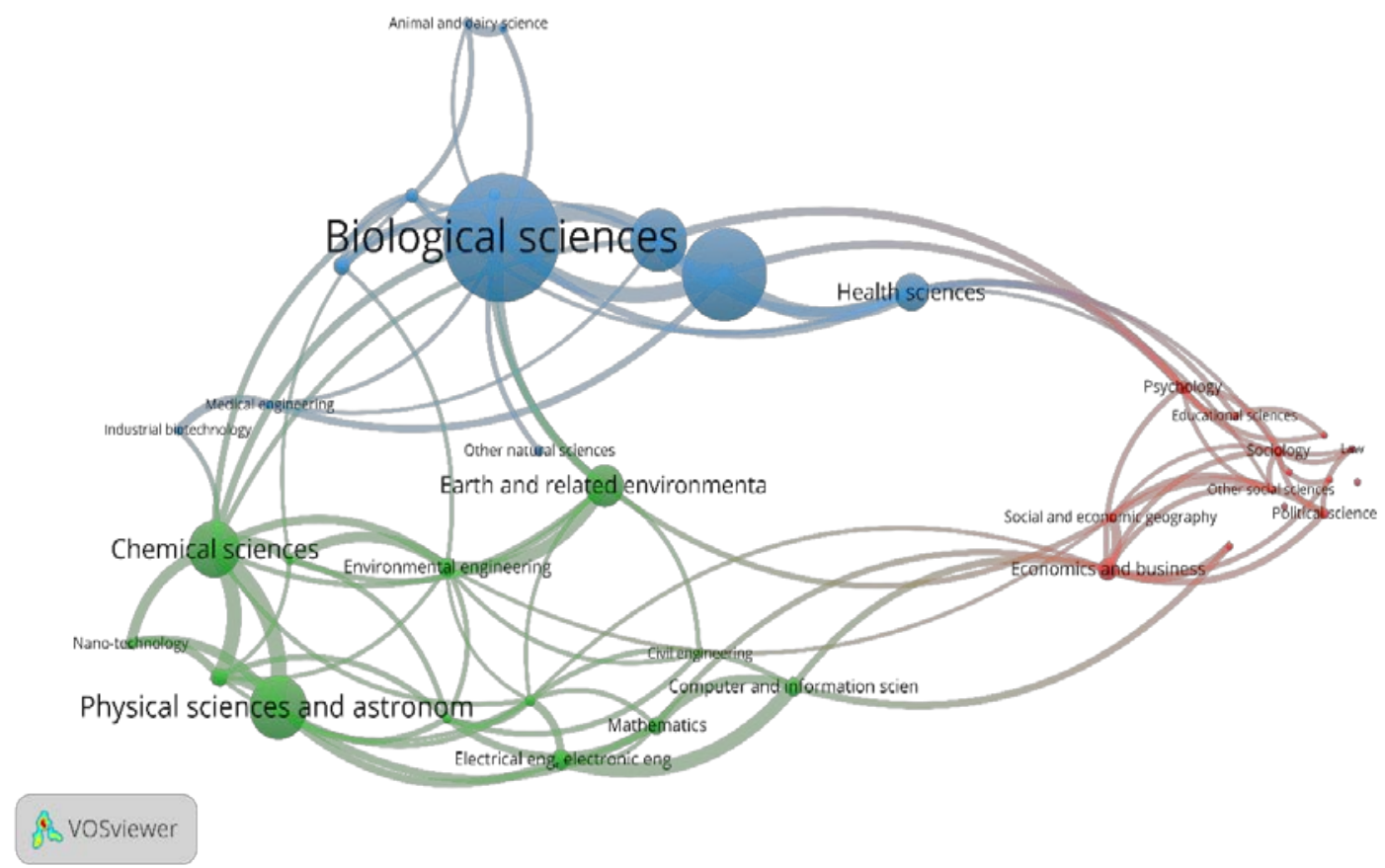

Figure 7. Funded research areas, and their citation relations.

The biological research areas have, in the examined period, attracted a total of 6.9 billion DKK, followed by 4.6 billion for basic medical research, and 2.8 billion to clinical research. This picture, however, also illustrates some of the difficulties of categorizing the type of research funded. The biological sciences, as they are defined by the OECD, comprise a broad mix of sub-disciplines spanning both human, animal, and plant biology. In our disciplinary map, the biological sciences are closely related to the medical research fields as seen from the strong citation link between these. The OECD categories may then obscure that a substantial amount of external funding is directed towards areas with a close affinity to basic medical research, such as microbiology, biochemistry, molecular biology, genetics, and virology. It is noteworthy that this degree of concentration is relatively similar across different types of funders. 


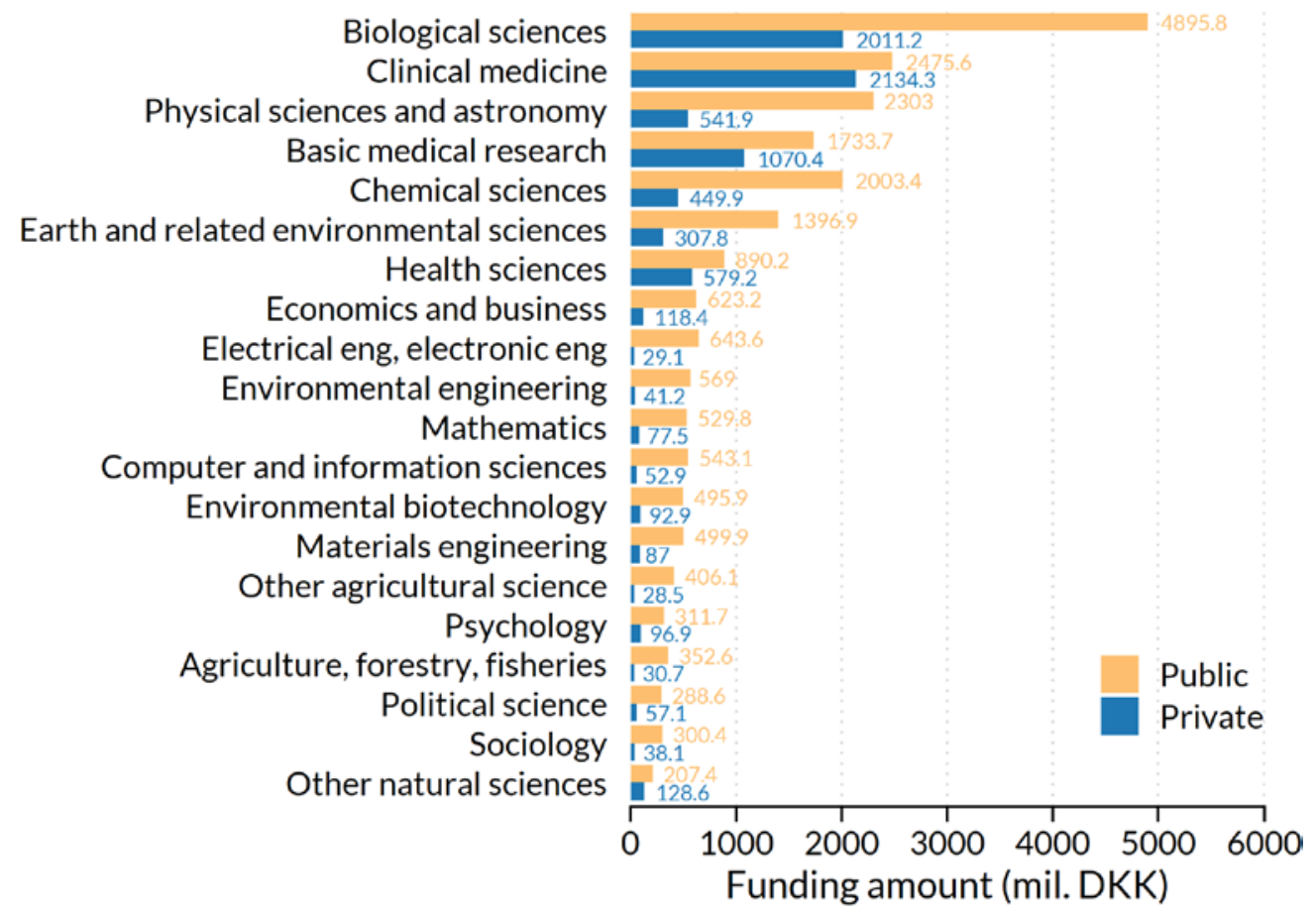

Figure 8. Public and private funding of research areas

Figure 8 shows the distributions of funding from public and private funders across the top 20 funded OECD areas. It is interesting to note that both type of funders largely prioritize similar, and relatively few, areas. Again, the biological sciences and clinical medicine are the top funded disciplines, the top seven areas are all within natural or biomedical sciences, and amass around $70 \%$ of total funding. $25 \%$ of areas get $73 \%$ of all funding from public funders, and $86 \%$ from private funders. So even though both types of funders prioritize a small set of areas, some differences still exist between their respective funding portfolios. While public funders direct the majority of their grants towards biology, physics, chemistry, and clinical and basic medicine, private funders focus primarily on biology and clinical medicine. This is not surprising given the composition of private Danish foundations where the largest ones are linked to the pharmaceutical industry.

\subsection{Concentration of research funding on disease specific topics}

At the aggregate level, the distribution of both public and private funding flows towards similar types of research as shown above. However, it is not clear whether this is a case of private priorities which "spill-over" into public funding, or simply a natural focus on the most important and promising areas from both types of funders. To investigate this further, we delve deeper into the distribution of funding within the biomedical area and compare funding of 134 disease categories with measures of their societal health burden. 

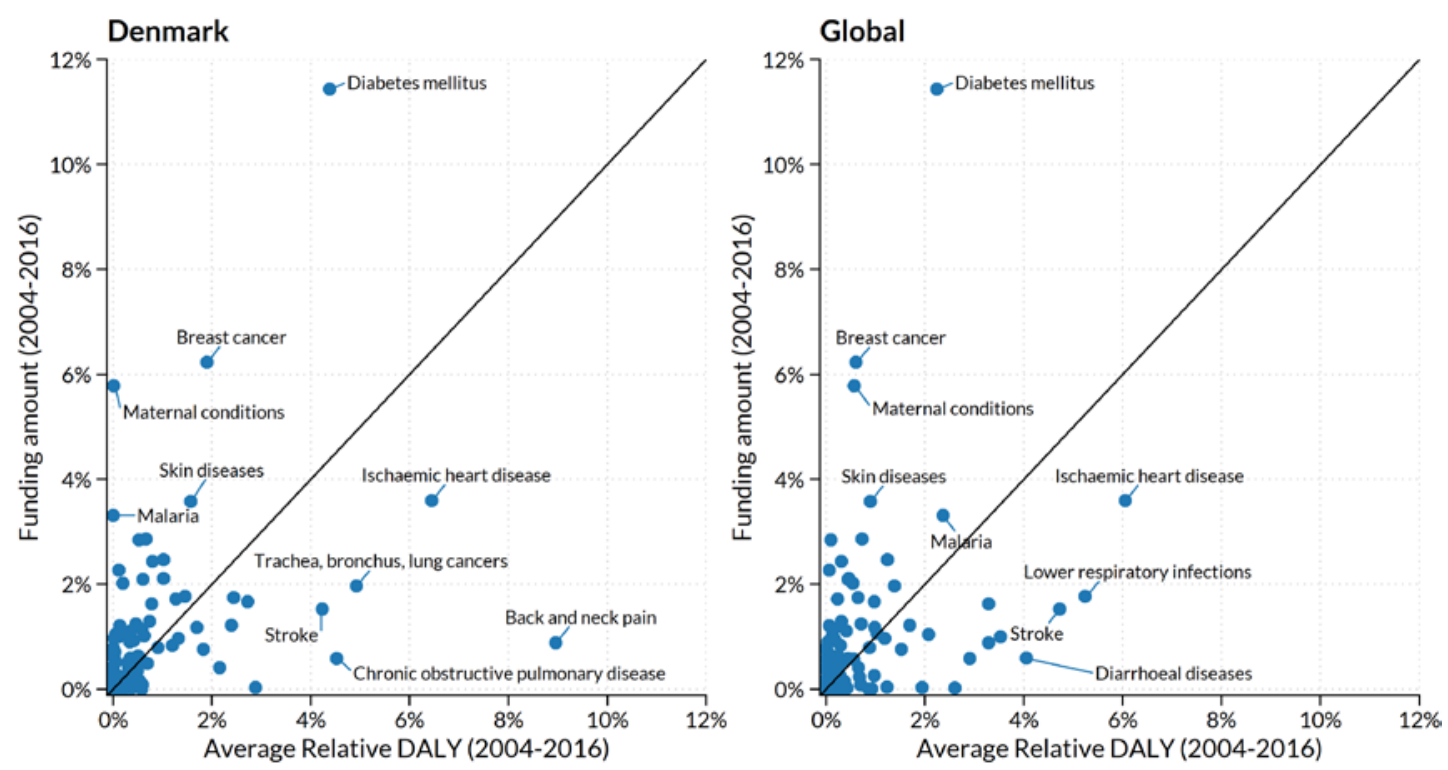

Figure 9. Relative disease burden and funding

Figure 9 shows the average relative burden, in the form of a disease's share of total disability-adjusted life-years against the relative funding amount for that disease. For the measure of relative disease burden, we have averaged the number of disabilityadjusted life years for a disease across 2004-2016, and calculated its share of total disability adjusted life years. The first plot is the average relative burden in Denmark, while the second shows the average relative burden at a global scale. In each plot, the diagonal shows a proportional relationship between burden and funding. The majority of diseases attract very little funding and pose a relatively small burden to societal health. A number of diseases are placed below the 45-degree line, indicating that their relative burden in Denmark is not matched by research investments. One example is back and neck pain, which constitutes $9 \%$ of total health burden but under $1 \%$ of total funding. Similar patterns apply for chronic obstructive pulmonary disease, ischemic heart disease and stroke. Another set of diseases above the diagonal receive a higher relative share of funding than their burden share. Diabetes is one such disease, which receives around $11.8 \%$ of all disease specific funding. Despite having a health burden almost equal to chronic pulmonary disease, diabetes receive ten times the amount of research funding. On the global scale, a group of diseases moves further towards the diagonal because the pose a larger health burden across the world. This is the case for malaria, diarrheal disease, and HIV/AIDS. Contrary, diseases such as breast cancer and skin diseases appear more "over financed" because they primarily affect people in high income countries (Yegros-Yegros et al., 2019).

The question is why some diseases, such as diabetes, draw so much funding relative to other diseases. Figure 10 may provide some answers to this. We calculated the 
funding percentile of each of the 134 diseases within the group of private and public funders and plotted these against each other.

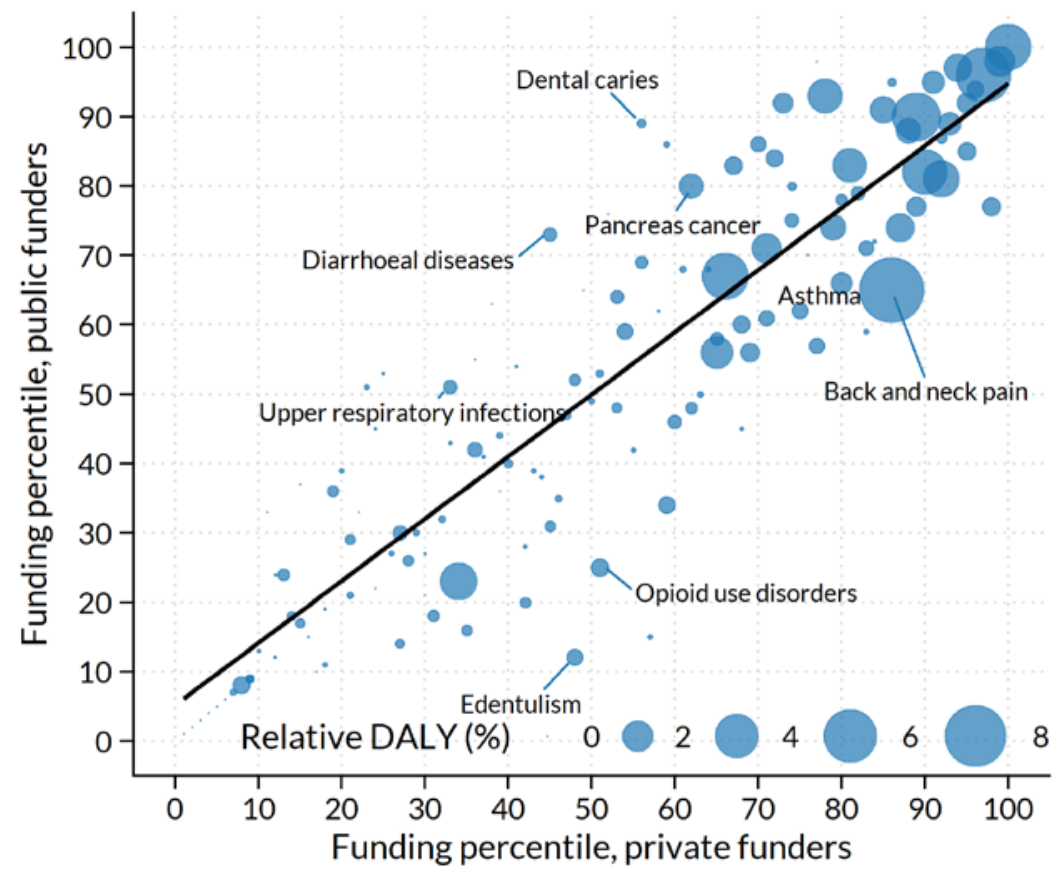

Figure 10. Funding percentiles for 134 disease areas in private and public funding bodies. $0=$ lowest, $100=$ highest.

The black regression line clearly shows the high correlation between the patterns of allocation by private and public funders with a correlation coefficient of almost 0.9 ( $r$ $=0.892$ ). Diabetes and breast cancer are the most funded diseases from both private and public funders. Diabetes draws 727 million DKK from public funders and 355.5 million from private funders, while breast cancer was awarded 331.6 million from public funders and 257.7 million from private funders. As both private and public funders tend to focus on a select subset of diseases with high burdens (represented by the size of each bubble), the concentration on few diseases increases. The figure also shows a great overlap in diseases not prioritized by both types of funders which indicates both a positive feedback mechanism for high funded diseases and a negative feedback mechanism for low funded diseases.

There are however also differences in the revealed funding patterns between the two types of funders. A range of neurological and psychiatric diseases are for instance more well-funded by private funders, and while e.g. Alzheimer's and dementia are within the top 10 most burdensome diseases in Denmark, $57.5 \%$ of funding for this disease is from private funders. Likewise, Schizophrenia, stroke, ischemic heart disease, and some types of cancer (breast, skin, brain) rely on over $40 \%$ of funding from private sources. Contrary, a range of diseases prevalent in other parts of the world, such as HIV/AIDS, lower respiratory infections and maternal complications 
receive only $25-30 \%$ of funding from private funding bodies. So even though priorities often line up across funders some functional division between them appears to exist where private money flows to disease areas relying on new medicine, while public resources are channeled toward well-studied diseases with a need for large-scale prevention interventions.

\section{Discussion: Drivers of funding concentration}

The Danish research funding system produces pronounced concentration with consequences for the research population as a whole, gender equality and topic selection. This degree of concentration is not least noteworthy since the Danish system is considered relatively egalitarian.

However, the scholarly literature does not offer convincing explanations of such allocation patterns. A main reason is most likely, that no simple explanation exists. Rather, there may be a number of mutually reinforcing causes interacting in various ways. In the following, we highlight potential drivers and relate them to the empirical findings in Section 4. While this approach is insufficient to draw clear causal conclusions, the findings raise important discussions and indicate how different drivers interact in a specific national context. This may in turn inform policy decisions and highlight needs for further comparative research.

\subsection{Internal and external drivers}

Concentration is not a new phenomenon. The institutional structure of science has always been biased toward concentration. Time and again, the pronounced inequality and the elitist nature of scientific activity has been demonstrated, most clearly manifested in the highly skewed distribution of productivity and recognition among scientists (Allison, 1980; Allison \& Stewart, 1974; Cole, 1970; Fox, 1983; Lotka, 1926; Merton, 1968; Price, 1963; Reskin, 1977; Zuckerman, 1970). Numerous historical examples have showed that even in cases where external pressures were marginal or absent, highly stratified systems have been the rule rather than the exception (Merton, 1968). Hence, some degree of selectivity in the allocation of funding has traditionally been seen as both natural and justified.

However, recent conscious and deliberate policy changes related to the funding and assessment of science may have amplified this inherent bias. Larger grants, increased support for critical mass and emphasis on initiatives to create 'world leading' environments are only some of such measures. Seen from this perspective increased funding concentration is both an intended and desired outcome.

But increased funding concentration may at the same time also be the result of less obvious and less deliberate factors. Two of these more hidden factors seem particularly important. The first concerns the dominant research quality criteria put 
to use when project proposals are assessed in multiple sites. If different funding agencies operate with relatively uniform criteria based on narrow notions of excellence (typically judged by elite peers and supported by metrics) priorities are likely to be mirrored even across fairly different funders. Hence, if a majority of funders all aim to pick and fund the 'best' researchers based on similar excellenceoriented quality criteria, the result is likely to be increased concentration.

This tendency can be further amplified by a second factor: a lack of oversight of allocation decisions made elsewhere in the system. In situations with limited coordination and transparency within and across grant bodies, the result may be higher concentration than any single funder or policy maker aim for. Even if each single grant decision in isolation is sound, the systemic effects may be undesirable when the majority of the funders select using identical parameters with many funders inadvertently ending up funding the same researchers and the same narrow topics. If this is the case, systems with a broad variety of funders may in fact risk ending up with higher degrees of concentration than systems with more centrally steered allocation decisions.

\subsection{Drivers in a Danish context}

The question is to what extent these potential explanations match the findings from section 4 . As we will show in the following all the above mentioned factors appear to have been present and active in the Danish case interacting to amplify concentration. First of all, the Danish system has experienced deliberate policy attempts to increase the level of competition as well as the degree of selectivity in the allocation of research funding over the past 15 years. As outlined in section 4 the share of project funding has increased from less than a third of the total research funding to nearly half. Alongside this, grant sizes have grown and success rates have dropped (Aagaard, 2017). An explicit policy aim has here been to try to raise the quality of Danish research through increased competition and by deliberately amplifying central elements in the institutional bias towards concentration.

Over time, the explicit aim of funding only the most excellent ideas has also become much more pronounced across all funders - public as well as private. In this situation, researchers who have high publication and citation performance and already have access to funding have been disproportionally likely to be further rewarded across the board. This is for instancereflected in the patterns of most of the top funded Danish researchers success in winning funding from many different funders. In addition, there are also indications that such self-reinforcing positive feedback loops initially may be set in motion by the private foundations. The private foundations with their additional funding and specific priorities are likely to give some researchers and some topics an upper hand, which subsequently may become amplified by the public 
funding organizations. Hence, when private foundations have specific topical interests and establish and support visible, impactful research groups, this has self reinforcing positive and negative feedback effects for the system as a whole. This trend may be even further amplified when the most successful grant recipients subsequently are rewarded with additional institutional funding via performance-based internal funding allocation criteria (Aagaard, 2017). In this way, the cycle may continue and perpetuate even further concentration.

Indications that self-reinforcing effects are active in the Danish system can not only be found at the individual level, but also at the topical level. As shown in the case study of disease specific research, there is large overlap in the priorities set by different funders. Even though both public research councils and private foundations focus the majority of their funds on disease areas with a relatively high disease burden, their common focus exacerbate the skew of the resource distribution. Part of the explanation of this overlap in priorities is likely to be an overlap in selection criteria between different funders. But it is also observed that public funding is least concentrated in research closest to patients, and that private sponsors therefore become primary funders of clinical research. These foundations may naturally focus on a narrow set of commercially viable areas (Rygård et al., 2018) and researchers working within these areas may have easier access to funding. Funding may then concentrate even further on both individuals and research topics.

When a preliminary version of this analysis was presented in Denmark in 2019 both funders, policymakers and stakeholders expressed surprise and concern over the actual degree of concentration on individuals and topics. Similarly, the distribution of funding across research areas also came as a surprise to most actors. Among all involved parties there was general agreement that better oversight and coordination is needed in the Danish system to ensure a more balanced overall investment portfolio. The impression given was also that the degree of selectivity and the actual priorities not only reflected deliberate decisions made with open eyes. To a large extent the results were also perceived as the result of information asymmetry to the benefit of the most successful researchers. The observed patterns appears in other words to be the result of both intended and unintended mechanisms reinforcing each other. Hence, at least in the case of Denmark, a pluralistic and decentralized funding system does not seem to lead to increased diversity - rather the opposite.

There are, however, two additional factors absent in this analysis, which need to be taken into account as well. The first of these is science internal and relates to the perceived prestige of different topics among researchers, journals, reviewers and funders. While it is hard to conceptualize and measure prestige at this level of aggregation, it can be assumed that prestige considerations to some extent get 
internalized in assessment criteria and notions of excellence. Hence, the prestige factor may further contribute to amplify the trend towards concentration. The second factor is mainly external and relates to grand societal challenges and other broad societal priorities. These priorities will in most cases be made from the top down and may create other dynamics across funders. Still, it is not evident whether societal priorities will amplify or weaken trends towards concentration. The societal priorities may in some cases be in opposition to the more science internal dynamics. Here the incentive structure of science, with its emphasis on priority and prestige, may in fact disincentivize scientists to study the most pressing societal problems. While most scientist most likely are motivated both by making scholarly contributions and solving pressing problems, dominant disciplinary quality criteria may limit the types problems they can address. Topic choice is however a complicated phenomenon and may be influenced by a host of factors, including expected academic returns, feasibility, possibilities to publish, costs of doing research, etc. (Leisyte \& Dee, 2012). So while the possibility to attract funding to some extent may influence topic choices (Gläser \& Laudel, 2016; Whitley et al., 2018), researchers in general appear to be hard to influence in terms of research directions (Myers, n.d.). Hence, the most effective instrument may not be specific programmes, but rather funder decisions not to fund certain topics (Gläser, 2019).

Societal priorities may thus in some cases lead to alternative research lines that would not otherwise have been followed resulting in increased diversity, but may also end up funding already existing research lines under new headings. In other cases - as shown in relation to the overlap in de facto priorities between public and private Danish funders - societal or specifc sectorial priorities may spark a self-reinforcing positive feedback circle, where successful applicants to mission oriented calls in turn also improve their chances of receiving more bottom up oriented funding. But since the present analysis has an underrepresentation of such societally oriented grants it is beyond this study to shed light on these types of dynamics in more detail.

\section{Conclusion and perspectives}

Overall, the empirical examinations presented in this study document a strong concentration of Danish research funding allocated by 15 of the largest Danish funders. These patterns of distribution are in particular found at the individual level, where a small proportion of the research population accounts for a very large share of the funding. In turn, it also results in a skewed gender balance as well as skewness in the relative weight of different research areas and more specialized research topics. This Danish situation appears at least partly to be a result of increased competition for external funding, decreasing success rates, many competing funding organisations 
using rather uniform excellence criteria and a general lack of coordination and oversight.

However, the dynamics outlined above are not unique to Denmark, but appear widespread and rising in many national funding systems around the world. Hence, similar or even greater funding concentration may be found in other national contexts. In this concluding section, we therefore discuss pros and cons of further developments towards concentration. The discussion first and foremost draws on a recent systematic literature review carried out by one of the authors of this article and two other colleagues (Aagaard et al., 2020).

Some arguments in the scholarly literature clearly favour at least some degree of concentration. A classical meritocratic argument is that the scientists with greatest potential to produce (potentially) path-breaking research should be rewarded according to their abilities. Economies of scale, critical mass, access to expensive instrumentation are other arguments. Funding concentration is furthermore argued to give increased flexibility to researchers, allowing them to take risks and pursue their research process with long time horizons. Finally, positive spill overs to nearby research environments, recruitment and collaboration effects are also mentioned. These all seem rather strong arguments and yet there are indications - as we return to below - that many of these apparent benefits might be achieved with moderate degrees of concentration without the potential systemically counter-productive effects of overly high concentration.

Arguments in favour of dispersal and diversity in particular highlight that the support of many lines of inquiry spreads risk and increases chances of breakthroughs by allowing for a broader variety of perspectives, interpretations and predictions. Likewise, chances of serendipity can also be assumed to increase with a multitude of competing approaches. Dispersal is simultaneously perceived to foster resilience in constantly changing research systems, where concentration on the other hand can lead to stagnation and reduced systemic adaptability. One reason is that large selfperpetuating research units may reduce the systemic capacity to respond flexibly. Large units may at the same time also turn talented group leaders into 'science managers' with little time for research and mentoring and with overly strong incentives and pressure to apply for and obtain ever more resources than can be productively spent. Dispersal on the other hand is seen as supporting a broader knowledge pool, creating absorptive capacity across systems as a whole and underpinning research-based teaching across all disciplines. In doing so, it may also secure a strong future growth layer of early and mid-career researchers and keep a broader group of researchers and students active in research. Finally, dispersal is 
argued as preferable as it reduces trends towards hyper-competition, and may mitigate a peer review system that is perceived as unreliable, subject to a number of biases and often unable to identify the most promising projects.

While the empirical evidence for most of these arguments is scattered, one result seems to be fairly robust. Multiple studies have shown that, on average, there is declining marginal return on funding invested in research above a certain threshold. Although this threshold varies across disciplinary and national boundaries, it is not generally - very high. However, reducing optimal funding to a question of evidence for or against concentration oversimplify a complex problem. The 'proper' balance between concentration and dispersal of research funding is more a matter of degree: both too little and too much concentration appears inefficient. Studies indicate that a healthy research system ecology includes both large and small groups (Wu et al. 2019). Furthermore, calls for greater diversity often seem to be interpreted as if all research can be perceived as equally good and equally important. This is obviously not the case and if diversity in itself becomes a target it may harm the overall development of science by diluting all quality concerns. As we highlight below the need for a well functioning quality assessment system may be even more pressing if more diversity should be pursued in a productive way, but it needs to build on a broader and more inclusive variety of academic and societal perspectives. Nonetheless, while the calls for diversity may be misused in certain situations, there are in general rather strong indications that most countries and fields need less, not more funding concentration.

A number of potential remedies can be highlighted if the aim is to reduce further concentration: First, better oversight is needed within and across funding organisations to ensure allocations based on broader portfolio perspectives and less on assessments of individual applications in isolation. In particular, there is a need to monitor the success of the older and more established researchers which appear to benefit the most from the lack of oversight. Secondly, experiments are needed with funding mechanisms seeking to counter the current concentration bias. A radical proposal here suggests widespread use of modified lottery models for grant applicants who pass an initial quality screening (Fang \& Casadevall, 2016). Others suggest experimentation with new funding instruments to promote risky research for instance by fully blinding the review process. These suggestions may however be at odds with aims to support more societally relevant research and should therefore only be a part of a broader portfolio of funding instruments. But most importantly, there is a need to start operating with broader understandings of research quality. Here it must be acknowledged more explicitly that 'excellence' is multifaceted and multidimensional. Hence, allocation mechanisms must be better equipped to capture 
and reward the inherent variety of academic and societal dimensions, but must do so without ending up in a situation where the concept of quality disappears completely.

\section{AUTHOR CONTRIBUTIONS}

Emil Bargmann Madsen: Conceptualization; Data curation; Formal analysis; Investigation; Methodology; Project administration; Software; Validation; Visualization; Writing - original draft; Writing - review \& editing.

Kaare Aagaard: Conceptualization; Data curation; Formal analysis; Funding acquisition; Investigation; Methodology; Project administration; Software; Validation; Writing - original draft; Writing - review \& editing.

\section{COMPETING INTERESTS}

The authors have no competing interests.

\section{FUNDING INFORMATION}

This work was supported by the Research Council of Norway, grant number 256223.

\section{DATA AVAILABILITY}

The data on individual research grants were obtained from individual public and private research funding organizations. Unfortunately, not all the funding organizations allow the data to be publicly available in a data repository. 


\section{References}

Aagaard, K. (2017). The Evolution of a National Research Funding System:

Transformative Change Through Layering and Displacement. Minerva, 55(3), 279-297. https://doi.org/10.1007/s11024-017-9317-1

Aagaard, K., Nielsen, M. W., \& Kladakis, A. (2020). Concentration or dispersal of research funding? Quantitative Science Studies, 1(1), 1-33.

https://doi.org/10.1162/qss

Alberts, B., Kirschner, M. W., Tilghman, S., \& Varmus, H. (2014). Rescuing US biomedical research from its systemic flaws. Proceedings of the National Academy of Sciences, 111(16), 5773-5777. https://doi.org/10.1073/pnas.1404402111

Allison, P. D. (1980). Inequality and Scientific Productivity. Social Studies of Science, 10(2), 163-179.

Allison, P. D., \& Stewart, J. A. (1974). Productivity differences among scientists: Evidence for accumulative advantage. American Sociological Review, 39(4), 596606.

Anand, S., \& Hanson, K. (1997). Disability-adjusted life years: a critical review. Journal of Health Economics, 16(6), 685-708.

Best, R. K. (2012). Disease Politics and Medical Research Funding. American Sociological Review, 77(5), 780-803. https://doi.org/10.1177/0003122412458509

Bol, T., de Vaan, M., \& van de Rijt, A. (2018). The Matthew effect in science funding. Proceedings of the National Academy of Sciences, 1-4. https://doi.org/10.1073/pnas.1719557115

Bowen, A., \& Casadevall, A. (2015). Increasing disparities between resource inputs and outcomes, as measured by certain health deliverables, in biomedical research. Proceedings of the National Academy of Sciences, 112(36), 11335-11340. https://doi.org/10.1073/pnas.1504955112

Bromham, L., Dinnage, R., \& Hua, X. (2016). Interdisciplinary research has consistently lower funding success. Nature, 534(7609), 684-687. https://doi.org/10.1038/nature18315

Cassi, L., Lahatte, A., Rafols, I., Sautier, P., \& de Turckheim, É. (2017). Improving fitness: Mapping research priorities against societal needs on obesity. Journal of Informetrics, 11(4), 1095-1113. https://doi.org/10.1016/j.joi.2017.09.010

Cole, S. (1970). Professional Standing and the Reception of Scientific Discoveries. American Journal of Sociology, 76(2), 286-306.

Cole, S., Cole, J. R., \& Simon, G. A. (1981). Chance and Consensus in Peer Review. 
Science, 214(4523), 881-886.

Evans, J. A., Shim, J. M., \& Ioannidis, J. P. A. (2014). Attention to local health burden and the global disparity of health research. PLoS ONE, 9(4), 1-9. https://doi.org/10.1371/journal.pone.0090147

Fang, F. C., \& Casadevall, A. (2016). Research Funding: the Case for a Modified Lottery. MBio, 7(2), e00694-16. https://doi.org/10.1128/mBio.00694-16

Fox, M. F. (1983). Publication Productivity among Scientists: A Critical Review. Social Studies of Science, 13(2), 285-305.

GBD 2017 DALYs and HALE Collaborators. (2018). Global, regional, and national disability-adjusted life-years (DALYs ) for 359 diseases and injuries and healthy life expectancy ( HALE) for 195 countries and territories , 1990 - 2017: a systematic analysis for the Global Burden of Disease Study 201. The Lancet, 392(10159), 1859-1922. https://doi.org/10.1016/S0140-6736(18)32335-3

Gillum, L. A., Gouveia, C., Dorsey, E. R., Pletcher, M., Mathers, C. D., Charles, E., \& Johnston, S. C. (2011). NIH Disease Funding Levels and Burden of Disease. PLoS ONE, 6(2), e16837. https://doi.org/10.1371/journal.pone.0016837

Gläser, J. (2019). How can governance change research content? Linking science policy studies to the sociology of science. In D. Simon, S. Kuhlmann, J. Stamm, \& W. Canzler (Eds.), Handbook on Science and Public Policy (pp. 419-447).

Cheltenham: Edward Elgar Publishing.

Gläser, J., \& Laudel, G. (2016). Governing Science. European Journal of Sociology, 57(01), 117-168. https://doi.org/10.1017/S0003975616000047

Gläser, J., \& Velarde, K. S. (2018). Changing Funding Arrangements and the Production of Scientific Knowledge: Introduction to the Special. Minerva, 56(1), 1-10. https://doi.org/10.1007/s11024-018-9344-6

Gross, C., Anderson, G., \& Powe, N. (1999). The Relation between Funding by the National Institutes of Health and the Burden of Disease. New England Journal of Medicine, 340(24), 1881-1887. https://doi.org/10.1056/NEJM199906173402406

Head, M. G., Fitchett, J. R., Nageshwaran, V., Kumari, N., Hayward, A., \& Atun, R. (2016). Research Investments in Global Health: A Systematic Analysis of UK Infectious Disease Research Funding and Global Health Metrics, 1997-2013. EBioMedicine, 3, 180-190. https://doi.org/10.1016/j.ebiom.2015.12.016

Hegde, D., \& Mowery, D. C. (2008). Politics and Funding in the U.S. Public Biomedical R\&D System. Science, 322(December), 1797-1798.

Hegde, D., \& Sampat, B. (2015). Can Private Money Buy Public Science? Disease Group Lobbying and Federal Funding for Biomedical Research. Management Science, 61(10), 2281-2298. https://doi.org/10.1287/mnsc.2014.2107 
Jones, R., \& Wilsdon, J. (2018). The Biomedical Bubble: Why UK research and innovation needs a greater diversity of priorities, politics, places and people. London: Nesta.

Katz, Y., \& Matter, U. (2019). Metrics of Inequality: The Concentration of Resources in the U.S. Biomedical Elite. Science as Culture, 0(0), 1-28. https://doi.org/10.1080/09505431.2019.1694882

Klavans, R., \& Boyack, K. W. (2017). Research portfolio analysis and topic prominence. Journal of Informetrics, 11(4), 1158-1174. https://doi.org/10.1016/j.joi.2017.10.002

Larivière, V., Macaluso, B., Archambault, É., \& Gingras, Y. (2010). Which scientific elites? On the concentration of research funds, publications and citations. Research Evaluation, 19(1), 45-53. https://doi.org/10.3152/095820210X492495

Leisyte, L., \& Dee, J. R. (2012). Understanding Academic Work in a Changing Institutional Environment. In J. Smart \& M. Paulsen (Eds.), Higher Education: Handbook of Theory and Research (vol. 25, pp. 123-206). Dordrecht: Springer.

Lerchenmueller, M. J., \& Sorenson, O. (2018). The gender gap in early career transitions in the life sciences. Research Policy, 47(6), 1007-1017. https://doi.org/10.1016/j.respol.2018.02.009

Li, D., \& Agha, L. (2015). Big names or big ideas: Do peer-review panels select the best science proposals? Science, 348(6233), 434-438. https://doi.org/10.1126/science.aaa0185

Lotka, A. J. (1926). The frequency distribution of scientific productivity. Journal of the Washington Academy of Sciences, 16(10), 317-323.

Ma, A., Mondragón, R. J., \& Latora, V. (2015). Anatomy of funded research in science. Proceedings of the National Academy of Sciences, 112(48), 14760-14765. https://doi.org/10.1073/pnas.1513651112

Manton, K. G., Gu, X.-L., Lowrimore, G., Ullian, A., \& Tolley, H. D. (2009). NIH funding trajectories and their correlations with US health dynamics from 1950 to 2004. Proceedings of the National Academy of Sciences, 106(27), 10981-10986. https://doi.org/10.1073/pnas.0905104106

Merton, R. K. (1968). The Matthew Effect in Science. Science, 159(3810), 56-63.

Mongeon, P., Brodeur, C., Beaudry, C., \& Lariviere, V. (2016). Concentration of research funding leads to decreasing marginal returns. Research Evaluation, 25(4), 396-404. https://doi.org/10.1093/reseval/rvw007

Mongeon, P., \& Paul-Hus, A. (2016). The journal coverage of Web of Science and Scopus: a comparative analysis. Scientometrics, 106(1), 213-228. https://doi.org/10.1007/s11192-015-1765-5 
Myers, K. (n.d.). The Elasticity of Science. American Economic Journal: Applied Economics, 1-38.

Parks, R. (2014). The Rise, Critique and Persistence of the DALY in Global Health. The Journal of Global Health, 4(1), 28-32.

Peifer, M. (2017). The argument for diversifying the NIH grant portfolio. Molecular Biology of the Cell, 28(22), 2935-2940. https://doi.org/10.1091/mbc.E17-07-0462

Price, D. J. D. S. (1963). Little Science, Big Science. New York, NY: Columbia University Press.

Reskin, B. F. (1977). Scientific Productivity and the Reward Structure of Science. American Sociological Review, 42(3), 491-504.

Rygård, S. L., Kjær, M.-B. N., \& Perner, A. (2018). Statens investering i kliniske forsøg. Ugeskrift for Læger, 180(16), 2-4.

Sörlin, S. (2007). Funding Diversity: Performance-based Funding Regimes as Drivers of Differentiation in Higher Education Systems. Higher Education Policy, 20(4), 413-440. https://doi.org/10.1057/palgrave.hep.8300165

Stoeger, T., Gerlach, M., Morimoto, R. I., \& Nunes Amaral, L. A. (2018). Large-scale investigation of the reasons why potentially important genes are ignored. PLoS Biology, 16(9), 1-25. https://doi.org/10.1371/journal.pbio.2006643

The Danish Council for Research and Innovation Policy. (2020). Forskningsfinansiering i Danmark - hvad er der i vente@ ? Copenhagen.

The Danish Government. (2006). PROGRESS, INNOVATION AND COHESION: Strategy for Denmark in the Global Economy. Copenhagen.

UFM. (2016). Private Fonde: En kortlægning af bidraget til dansk forskning, innovation og videregående uddannelse. København.

UK Clinical Research Collaboration. (2015). UK Health Research Analysis 2014. London.

Wahls, W. P. (2018a). High cost of bias: Diminishing marginal returns on NIH grant funding to institutions. BioRxiv. https://doi.org/10.1101/367847

Wahls, W. P. (2018b). The NIH must reduce disparities in funding to maximize its return on investments from taxpayers. ELife, 7, 1-9.

https://doi.org/10.7554/eLife.34965

Wang, J., Lee, Y. N., \& Walsh, J. P. (2018). Funding model and creativity in science: Competitive versus block funding and status contingency effects. Research Policy, 47(6), 1070-1083. https://doi.org/10.1016/j.respol.2018.03.014

Whitley, R., Gläser, J., \& Laudel, G. (2018). The Impact of Changing Funding and 
Authority Relationships on Scientific Innovations. Minerva, 56(1), 109-134. https://doi.org/10.1007/s11024-018-9343-7

Yao, L., Li, Y., Ghosh, S., Evans, J. A., \& Rzhetsky, A. (2015). Health ROI as a measure of misalignment of biomedical needs and resources. Nature Biotechnology, 33(8), 807-811. https://doi.org/10.1038/nbt.3276

Yegros-Yegros, A., Klippe, W. Van De, Abad-Garcia, M.-F., \& Rafols, I. (2019).

Exploring why global health needs are unmet by public research efforts : the potential influences of geography, industry, and publication incentives.

https://doi.org/10.2139/ssrn.3459230

Zuckerman, H. (1970). Stratification in American Science. Sociological Inquiry, 40(2), 235-257. 


\section{Appendix}

Table A1. Summary statistics for full and Web of Science-matched samples

\begin{tabular}{lcc}
\hline & Full sample & WoS-matched sample \\
\hline Female grantees & $29 \%$ & $27 \%$ \\
Funding amount & & \\
Mean & $2,472,936$ & $2,650,834$ \\
Median & 934,001 & $1,000,000$ \\
Grant type & & \\
Research project & $56,2 \%$ & 59,1 \\
Postdoc grant & $12,6 \%$ & $10,9 \%$ \\
Studentship grants & $7,1 \%$ & $7,5 \%$ \\
Mobility grants & $5,8 \%$ & $5,3 \%$ \\
Infrastructure grants & $4,2 \%$ & $5,2 \%$ \\
\hline
\end{tabular}

Table A2. Percentiles of funding for full and Web of Science-matched samples

\begin{tabular}{ccc}
\hline Percentiles & Full sample & WoS-matched sample \\
\hline 10 th & 120,000 & $133,798.4$ \\
20 & 200,000 & $221,702.4$ \\
30 & 350,000 & 400,000 \\
40 & 513,399 & 600,000 \\
50 & 970,076 & $1,000,000$ \\
60 & $1,367,621$ & $1,465,663.8$ \\
70 & $1,824,608$ & $1,977,948.3$ \\
80 & $2,586,948$ & $2,750,013.8$ \\
90 th & $5,573,906$ & $5,796,784.9$ \\
\hline
\end{tabular}


Table A3. Summary of cumulative funding amounts by academic age

\begin{tabular}{ccccccc}
\hline $\begin{array}{c}\text { Academic } \\
\text { age }\end{array}$ & $\begin{array}{c}\text { Mean } \\
\text { amount }\end{array}$ & $\begin{array}{c}\text { Median } \\
\text { amount }\end{array}$ & Std. Dev. & $\begin{array}{c}\text { 25th } \\
\text { percentile }\end{array}$ & $\begin{array}{c}75 \text { th } \\
\text { percentile }\end{array}$ & N \\
\hline 1 & $2,059,150$ & $1,394,369$ & $3,982,689$ & 465,050 & $2,272,460$ & 203 \\
2 & $1,916,986$ & $1,406,368$ & $2,838,634$ & $491,842.2$ & $2,216,921$ & 274 \\
3 & $2,359,436$ & $1,281,250$ & $4,524,869$ & 612,500 & $2,319,287$ & 289 \\
4 & $2,318,330$ & $1,430,635$ & $5,613,875$ & 475,133 & $2,639,520$ & 365 \\
5 & $3,560,705$ & $1,471,361$ & $8,873,202$ & $457,283.5$ & $2,920,518$ & 360 \\
6 & $3,919,500$ & $1,811,427$ & $6,725,612$ & 700,000 & $3,692,522$ & 287 \\
7 & $5,212,371$ & $1,975,000$ & $8,913,655$ & 678,674 & $5,845,278$ & 277 \\
8 & $5,816,947$ & $2,587,626$ & $9,279,674$ & 759,628 & $6,367,089$ & 298 \\
9 & $8,104,687$ & $3,548,362$ & $12,941,586$ & $1,288,375.5$ & $10,807,996$ & 204 \\
10 & $9,013,589$ & $4,231,821$ & $13,069,892$ & $1,995,207.8$ & $10,319,452$ & 224 \\
11 & $10,519,679$ & $5,845,956$ & $16,244,098$ & $2,048,200$ & $12,443,770$ & 206 \\
12 & $11,831,184$ & $4,406,880$ & $27,560,715$ & $1,416,200$ & $10,331,734$ & 247 \\
13 & $16,941,984$ & $6,237,916$ & $30,578,227$ & $2,464,663.8$ & $15,520,343$ & 214 \\
14 & $12,040,523$ & $6,037,999$ & $17,240,231$ & $2,274,275$ & $14,029,316$ & 217 \\
15 & $18,532,573$ & $8,334,335$ & $28,180,229$ & $3,959,349$ & $20,939,255$ & 233 \\
$16+$ & $20,350,703$ & $10,503,805$ & $28,182,465$ & $4,257,937$ & $20,436,796$ & 150 \\
\hline
\end{tabular}
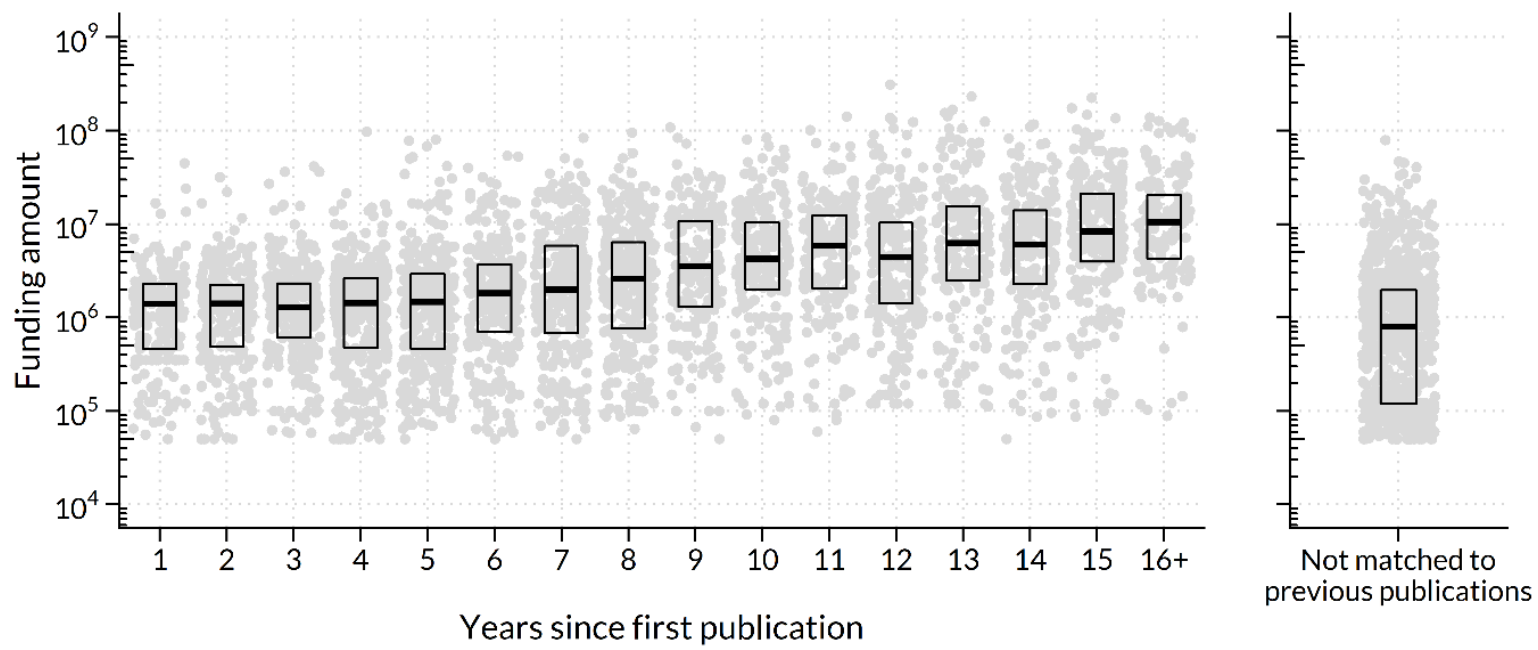

Figure A1. Distribution of cumulative funding across academic age. Boxplots show $25^{\text {th }}, 50^{\text {th }}$ and $75^{\text {th }}$ percentile. 